\title{
Does antennal sensilla pattern of different populations of Triatoma maculata (Hemiptera: Reduviidae) reveal phenotypic variability?
}

Josiane Nogueira Müller ${ }^{1}$, Teresa Cristina Monte Gonçalves ${ }^{1 *}$, Alice Helena Ricardo-Silva?, Amanda Coutinho Souza ${ }^{2}$, Francisco Maciel Santos ${ }^{3}$, Rosangela Santos ${ }^{3}$, Nathalia Coelho Vargas ${ }^{3}$, Catarina Macedo Lopes ${ }^{1}$ and Ana Laura Carbajal-de-la-Fuente ${ }^{4,5,6}$

\begin{abstract}
Background: In Brazil, Triatoma maculata is only found in the State of Roraima and is a vector of Trypanosoma cruzi, the etiological agent of Chagas disease. It occurs in wild, peridomestic and domestic habitats, with an urban infestation in Boa Vista, the capital of this Brazilian state. The aim of this study was to assess the morphological variability of the T. maculata antennal phenotype in three populations of Roraima State, using the antennal sensilla pattern analyzed under optical microscopy.

Methods: The number and distribution of four antennal sensilla types (bristles, thin and thick walled trichoidea, and basiconic) of three Brazilian populations of T. maculata from Roraima State were compared. Univariate and multivariate analyses were performed.

Results: The antenna of T. maculata presented the four types of sensilla. According to the density and distribution of the antennal sensilla characteristics, the multivariate analyses showed that the laboratory population is morphologically structured. Urban specimens showed a pronounced phenotypic variability. The main differences were observed in the pedicel segment, and between males and females.

Conclusions: We determined the antennal phenotype in three Roraima populations of T. maculata. These results support the idea that the patterns of antennal sensilla are sensitive markers for distinct populations in the Triatominae. The infestations of T. maculata in different habitats reinforces the ability of this vector to become adapted to a variety of environments, which, could have eco-epidemiological implications for the T. cruzi transmission that are still not well understood.
\end{abstract}

Keywords: Triatominae populations, Antennal phenotype, Roraima, Brazil

\section{Background}

Chagas disease, caused by Trypanosoma cruzi (Chagas, 1909), is mostly transmitted by blood-sucking bugs of the subfamily Triatominae. Triatoma maculata (Erichson, 1848), a vector of T. cruzi, is distributed in the northern

\footnotetext{
*Correspondence: tcmontegoncalves@gmail.com

${ }^{1}$ Laboratório Interdisciplinar de Vigilância Entomológica em Diptera e Hemiptera, Instituto Oswaldo Cruz/ Fiocruz, Rio de Janeiro, RJ, Brasil

Full list of author information is available at the end of the article
}

regions of South America and in Brazil, where it is only found in the State of Roraima [1]. It occurs in wild habitats, in palms of the genus Attalea and is associated with opossums (Didelphis marsupialis), birds and bats [2]. In peridomestic environments, it is associated with chicken coops and pigeon nests [2]. In the State of Roraima, a domiciliary infestation of T. maculata was found [3] and recently, an infestation was recorded in an urban area of a residential neighbourhood in the city of Boa Vista [4].

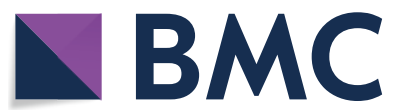

(c) The Author(s) 2019. This article is licensed under a Creative Commons Attribution 4.0 International License, which permits use, sharing, adaptation, distribution and reproduction in any medium or format, as long as you give appropriate credit to the original author(s) and the source, provide a link to the Creative Commons licence, and indicate if changes were made. The images or other third party material in this article are included in the article's Creative Commons licence, unless indicated otherwise in a credit line to the material. If material is not included in the article's Creative Commons licence and your intended use is not permitted by statutory regulation or exceeds the permitted use, you will need to obtain permission directly from the copyright holder. To view a copy of this licence, visit http://creativeco mmons.org/licenses/by/4.0/. The Creative Commons Public Domain Dedication waiver (http://creativecommons.org/publicdomain/ zero/1.0/) applies to the data made available in this article, unless otherwise stated in a credit line to the data. 
The insects have flexibility in the expression of characters, contributing to adaptability to various environments. This flexibility is called phenotypic variability and is considered essential for understanding the development and maintenance of morphological variation [5]. In triatomines, the phenotype may vary because of the ability to feed on different hosts, to adapt to the environments where it developed, and to vary the host-vector contact rates, among other factors [2]. Consequently, phenotypic variation is an adaptive response, which can vary physiological processes in response to environmental pressures [6].

The triatomines perceive sensorial stimuli from the environment by receptors located mainly on the antennae denominated sensilla; these are classified as mechanoreceptors and chemoreceptors [7]. Among the chemoreceptive sensilla are those that detect chemical components related to food sources, recognize sexual partners, and locate preferred habitats [7]. The antennal phenotype consists of the type and number of sensilla distributed on the antenna and is considered an indicator of the adaptation of the triatomines to ecotopes of different complexities and stabilities [6]. It provides an efficient and low-cost response to determine the morphological variability among genera, species and populations [7-9].

In Brazil, T. maculata is considered one of the species of epidemiological importance [10]. As part of an interdisciplinary study on the eco-epidemiological aspects conducted in the area, an integral project involving research, education, and health services was conducted. The abundance and infestation of domestic and peridomestic sites by T. maculata were determined, as well as their infection with T. cruzi and their feeding sources [3]. Simultaneously, an urban infestation was detected in Boa Vista [4]. In this context, we studied the morphological variability of $T$. maculata antennal phenotype. We included peridomestic populations of Amajari, Bonfim and a population with 18 generations maintained in the laboratory (all from Roraima State). Sexual dimorphism was also explored.

\section{Methods}

Three Brazilian populations of T. maculata from Roraima State were compared: from Amajari $\left(03^{\circ} 39^{\prime} 07^{\prime \prime} \mathrm{N}\right.$, $\left.61^{\circ} 22^{\prime} 15^{\prime \prime} \mathrm{W}\right)$; Bonfim $\left(03^{\circ} 21^{\prime} 36^{\prime \prime} \mathrm{N}, \quad 59^{\circ} 49^{\prime} 58^{\prime \prime} \mathrm{W}\right)$; and a laboratory colony from Uiramutã $\left(04^{\circ} 35^{\prime} 45^{\prime \prime} \mathrm{N}\right.$, $\left.60^{\circ} 10^{\prime} 4^{\prime \prime} \mathrm{W}\right)$. Triatomines were collected during 20142015 by active search. The field adults were collected in chicken coops, except for the laboratory colony. This colony was originated from adult specimens $(n=38)$ feeding on mice (License P0100-01 CEUA-FIOCRUZ) and is maintained in the insectary of the Laboratório Interdisciplinar de Vigilância Entomológica em Diptera e Hemiptera, Instituto Oswaldo Cruz, FIOCRUZ, Brazil. The insects studied were from a colony of 18 th generation. A total of 15 males and 15 females from three populations of T. maculata were included in this study and were identified following a dichotomous key traditionally used for this purpose [11].

One right antenna per individual was removed using fine forceps, stored in $70 \%$ ethanol according to previous protocols [8]. Sensilla identification and counting were made on the ventral side of the three distal segments of the antenna [pedicel (P); flagellum first segment (F1); and flagellum second segment (F2)] using optical microscopy (Leica, DMLS, Wetzlar, Germany) $(400 \times)$ and a drawing chamber (ISH 1000, Tucsen, Australia). Sensilla were classified as follows: bristles (BR); thin-walled trichoids (TH); thick-walled trichoids (TK); and basiconic (BA) [8]. Means and standard deviations were calculated for each type of sensilla in each of the antennal segments.

Levene's test was used to check the homogeneity of variances. Variables were analyzed using ANOVA and mean values were contrasted using Tukey's post-hoc test. Variables with significant differences were used for a discriminant analysis. Mahalanobis distances were calculated as the distance between group centroids generated by the discriminant functions. Their statistical significance was calculated through permutation tests $(1000$ runs each) and was corrected by means of the Bonferroni method. A cross-check classification was used to validate the classification of the individuals in the discriminant analysis. A few adult specimens $(n=3)$ from Boa Vista city $\left(02^{\circ} 49^{\prime} 12^{\prime \prime} \mathrm{N}, 60^{\circ} 40^{\prime} 19^{\prime \prime} \mathrm{W}\right)$ collected at domiciles were used in this study. Because of this low number, it was not possible to incorporate them into the ANOVA. However, it was possible to include them one by one in the discriminant analysis as 'unknown specimens' [12]. This allowed for the determination of the similarity of each individual to the reference population. The ANOVA was carried out using JMP v. 6.0.0 (SAS Institute Inc., 2005) and discriminant analysis was performed using the CLIC v. 98 package (http://xyom-clic.eu/).

\section{Results}

The antenna of T. maculata presented four types of sensilla distributed on three segments (Table 1). All variables showed variance homoscedasticity except for TH pedicel. Significant differences between the Amajari and laboratory populations were detected in the number of F2-TK sensilla (Tukey's post-hoc tests, all $P<0.05)$. There were also significant differences for the number of F1-BR sensilla of the Amajari populations and P-BR sensilla of the laboratory population (data not shown). ANOVA test for sensilla numbers revealed significant differences between sexes $\left(F_{(1,28)}=9.71\right.$, 


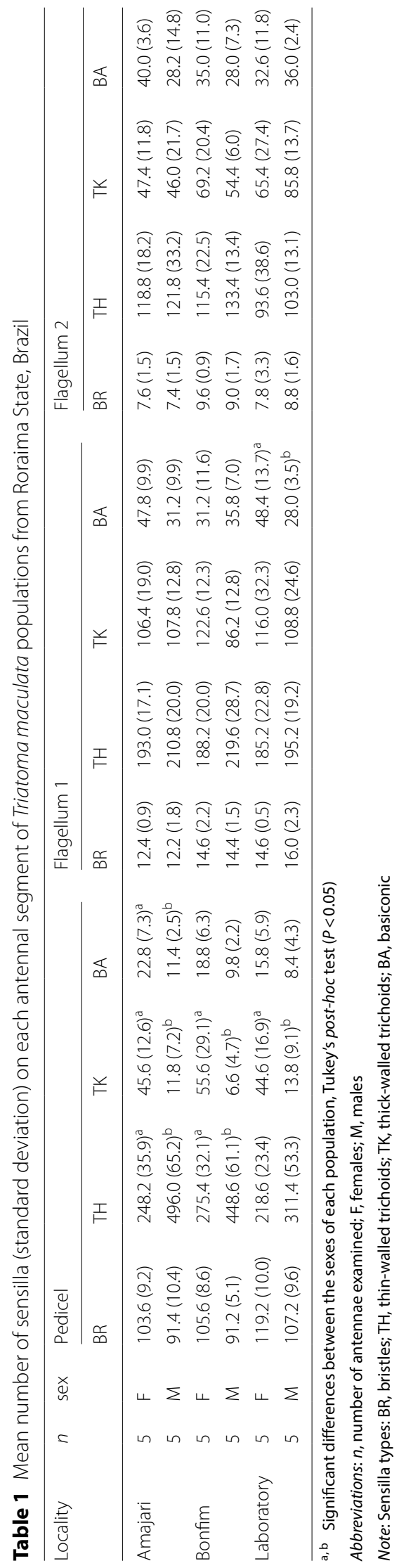


$P=0.0042)$. Tukey's post-hoc test showed a sexual dimorphism for Amajari, Bonfim and laboratory populations mainly for sensilla on the pedicel segment (all $P<0.05$ ) (Table 1).

The multivariate analysis performed using three significant variables (number of P-BR, F1-BR and F2-TK sensilla) showed that the first two discriminant factors accounted for $89 \%$ and $11 \%$ of the total variation, respectively. The factorial distribution map of the individuals in the first plane of the discriminant analysis and based on the Mahalanobis distances showed low discrimination between groups in this space (Fig. 1). The Mahalanobis distances showed that the laboratory population was significantly different from the populations of Amajari (Mahalanobis distance $=2.72 ; P<0.01$ ) and Bonfim (Mahalanobis distance $=1.71 ; P<0.01$ ). The cross-checked classification (1000 permutations) revealed that $80 \%$ of the laboratory specimens were correctly classified. However, for the individuals of the Amajari and Bonfim populations, the classification values were $60 \%$ and $40 \%$, respectively. Because of the low number of individuals from Boa Vista $(n=3)$, they were included one by one in the discriminant analysis as 'unknown specimens'. The results showed that they were similar to each one of three studied populations, suggesting an antennal phenotypic heterogeneity (Fig. 1).

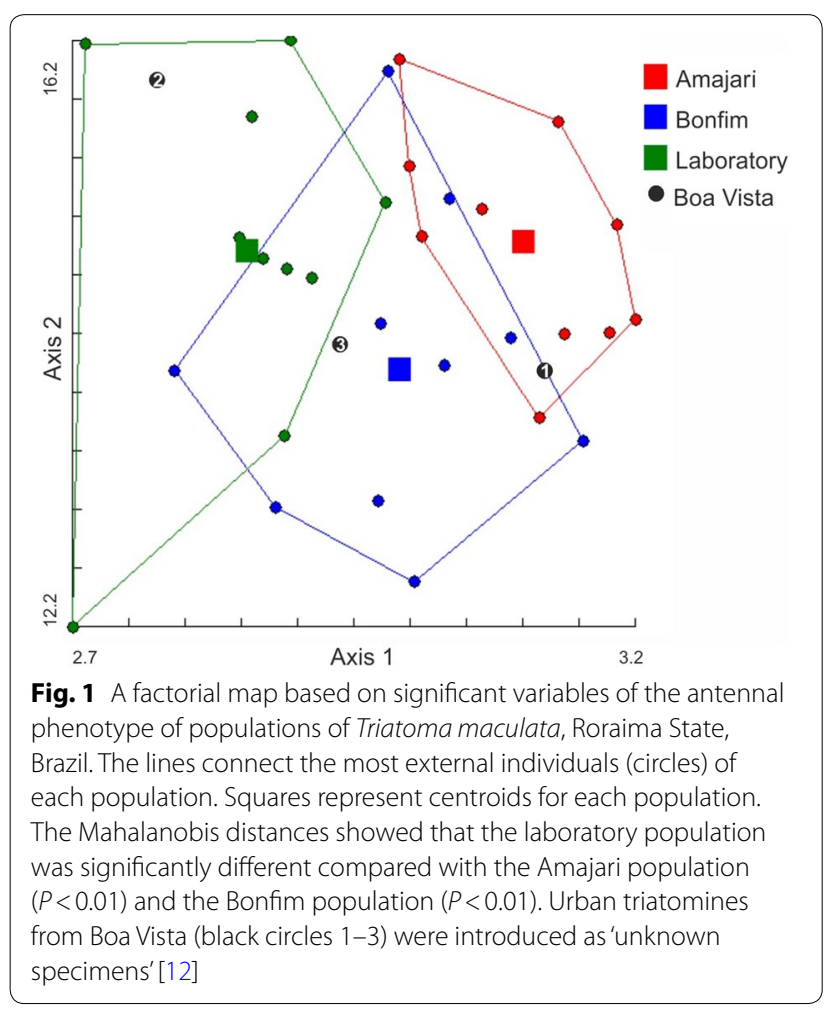

\section{Discussion}

The multivariate analysis showed that the laboratory population is morphologically structured and the specimens of the urban population showing phenotypic variability. Based on the univariate analysis, the main difference was found in the pedicel with the number of thick walled trichoids (TK) on this segment, being significantly different between males and females of the three populations. Sexual dimorphism in the antennal phenotype of triatomines has been reported in other Brazilian species, such as Triatoma sordida and Triatoma pseudomaculata [9] and T. maculata [8].

Diversity in the type and number of receptors in the pedicel was observed in four species of the genus Triatoma, which could be related to the characteristics of the habitat where each species evolved [9]. The pedicel of $T$. maculata populations of Amajari and Bonfim, collected from the peridomicile (chicken coop) environment, is complex, they show a higher density of sensilla than in sylvatic T. maculata [8]. These results suggest that species that develop in multiple habitats and are not very stable (e.g. T. sordida, T. pseudomaculata), present more types and a greater number of sensilla in the pedicel [7]. Moreover, T. maculata individuals raised under stable conditions of temperature, humidity, and frequent feeding in the laboratory, had a pedicel with fewer sensilla. Considering the laboratory as a new habitat for triatomines, many authors showed morphological changes associated with different rearing conditions [13] also observed in the present study in the laboratory population. In this sense, the antennal sensilla of triatomines showed a degree of morphological variability among populations that seemed to be associated with adaptations based on the sensorial requirements of different habitats [7]. Thus, it would seem logical to expect that a population developed in a laboratory habitat, which undoubtedly differs from its natural habitat, presents changes in the antennal phenotype ([13, 14]; the present study).

Our study presents some limitations, such as a low number of individuals, allowing only simple descriptive analysis. In addition, it was not possible to include a population of T. maculata collected in the wild, which would have allowed other comparisons in relationship to ecotopes. However, similar results were reported for the antennal phenotype of the pedicel of individuals collected in palm trees from wild areas of the state of Roraima, Brazil [8]. Microhabitats with a stable temperature and humidity, such as the base of the palm leaf where the triatomines grow, as well as stable environments with temperature, humidity, and feeding under controlled laboratory conditions, could reflect this similarity. This not only supports the idea of morphological plasticity but also suggests caution in the use of long-term laboratory 
material for morphological studies [14]. The individuals from the urban area of Boa Vista, which were placed in the discriminant analysis as 'unknown', showed phenotypic similarities with the laboratory population, the Amajari and Bonfim populations. Because this was an exploratory analysis with a low number of individuals, it was not possible to interpret the results without speculation. However, the occurrence of T. maculata in different habitats may suggest the ability of this vector to adapt to a variety of environments, which could have eco-epidemiological implications that are still not well known [4, 15-17]. In agreement with Noireau et al. [18], although anthropogenic environmental changes and successive damage to the habitats of triatomines could promote dispersal and favour the domiciliation process, the basic mechanisms of adaptation of these insects to artificial ecotopes remain poorly understood.

\section{Conclusions}

We determined the antennal phenotype of three Roraima populations of $T$. maculata. The laboratory population was morphologically structured in relation to the density and distribution of the antennal sensilla. The urban individuals from Boa Vista showed a pronounced phenotypic variability. The main differences were in the pedicel and between males and females of the three populations. These results support the idea that the patterns of antennal sensilla are sensitive markers for distinct populations in the Triatominae.

\section{Abbreviations \\ P: pedicel; F1: flagellum first segment; F2: flagellum second segment; BR: bristles; TH: thin-walled trichoids; TK: thick-walled trichoids; BA: basiconic.}

\section{Acknowledgements}

We thank Núcleo de Entomologia da Secretaria de Saúde do Estado de Roraima for logistical support and professionals to assist in field practice. Thanks are due to Dr Ângela Junqueira, Laboratório de Doenças Parasitárias, FIOCRUZ, for the use of their infrastructure and also the anonymous reviewers for their helpful comments.

\section{Authors' contributions}

JNM, ALCF and TCMG conceived and designed the experiments. JNM, AHRS, FMS, RS and NCV collected the insects. JNM, ALCF, TCMG and CML analyzed the data. ALCF and TCMG wrote the manuscript. All authors read and approved the final manuscript.

\section{Funding}

This study was supported by grants from Instituto Oswaldo Cruz/ FIOCRUZ (CNPJ: 33781055000135), Rio de Janeiro and Coordenação de Aperfeiçoamento de Pessoal de Nível Superior (CAPES), Brazil. The funding sources had no role in study design, data collection and analysis, decision to publish, or preparation of the manuscript.

\section{Availability of data and materials}

The datasets used and/or analyzed during the present study available from the corresponding author upon reasonable request.

Ethics approval and consent to participate Not applicable.

\section{Consent for publication}

Not applicable.

\section{Competing interests}

The authors declare that they have no competing interests.

\section{Author details}

${ }^{1}$ Laboratório Interdisciplinar de Vigilância Entomológica em Diptera e Hemiptera, Instituto Oswaldo Cruz/ Fiocruz, Rio de Janeiro, RJ, Brasil. ${ }^{2}$ Laboratório de Doenças Parasitárias, Instituto Oswaldo Cruz/Fiocruz, Rio de Janeiro, RJ, Brasil. ${ }^{3}$ Núcleo de Entomologia, Secretaria de Saúde do Estado de Roraima, Boa Vista, Brasil. ${ }^{4}$ Laboratorio de Eco-Epidemiología, Departamento de Ecología, Genética y Evolución, Facultad de Ciencias Exactas y Naturales, Universidad de Buenos Aires, Buenos Aires, Argentina. ${ }^{5}$ Instituto de Ecología, Genética y Evolución de Buenos Aires (IEGEBA), CONICET-Universidad de Buenos Aires, Ciudad Autónoma de Buenos Aires, Argentina. ${ }^{6}$ Centro Nacional de Diagnóstico e Investigación en Endemo-Epidemias (CeNDIE), Administración Nacional de Laboratorios e Institutos de Salud “Dr. Carlos Malbrán” (ANLIS), Ciudad Autónoma de Buenos Aires, Argentina.

Received: 13 June 2019 Accepted: 16 December 2019

Published online: 23 December 2019

\section{References}

1. Abad-Franch F, Campos C, Santos WS, Barrett TV. Chagas Disease and its vectors (Triatominae) in the state of Roraima. In: Barbosa R, Ferreira-Melo V, editors. Roraima Homen, Ambiente e Ecolologia. Manaos: INPA-UFRR; 2010. p. 453-84.

2. Cantillo-Barraza O, Garcés E, Gómez-Palacio A, Cortés LA, Pereira A, Marcet PL, et al. Eco-epidemiological study of an endemic Chagas disease region in northern Colombia reveals the importance of Triatoma maculata (Hemiptera: Reduviidae), dogs and Didelphis marsupialis in Trypanosoma cruzi maintenance. Parasit Vectors. 2015:8:482

3. Ricardo-Silva A. Abordagens ecológicas sobre Triatoma maculata (Erichson, 1848) e ações de educação visando a prevenção da doença de Chagas no Estado de Roraima. PhD thesis. Instituto Oswaldo Cruz, FIOCRUZ, Rio de Janeiro, Brazil; 2017.

4. Ricardo-Silva A, Gonçalves TCM, Luitgards-Moura JF, Lopes CM, da Silva $\mathrm{SP}$, Bastos AQ, et al. Triatoma maculata colonises urban domicilies in Boa Vista, Roraima, Brazil. Mem Inst Oswaldo Cruz. 2016;111:703-6.

5. Pigliucci M. Evolution of phenotypic plasticity: Where are we going now? Trends Ecol Evol. 2005:20:481-6.

6. Dujardin JP, Costa J, Bustamante D, Jaramillo N, Catalá S. Deciphering morphology in Triatominae: the evolutionary signals. Acta Trop. 2009;110:101-11

7. Catalá S. Antennal sensilla of Triatominae (Hempitera, Reduviidae): a comparative study of five genera. Int J Insects Morphol Embryol. 1997:26:67-73.

8. Carbajal-de-la-Fuente AL, Noireau F, Catalá SS. Inferences about antennal phenotype: the "Triatoma maculata complex" (Hemiptera: Triatominae) is valid? Acta Trop. 2008:106:16-21.

9. Carbajal-de-la-Fuente AL, Catalá S. Relationship between antennal sensilla pattern and habitat in six species of Triatominae. Mem Inst Oswaldo Cruz. 2002;97:1121-5

10. Ministério de Saúde. Doença de Chagas aguda no Brasil: série histórica de 2000 a 2013. Bol Epidemiológico Secr Vigilância em Saúde; 2015. http:// portalsaude.saude.gov.br/images/pdf/2015/agosto/03/2014-020..pdf. Accessed 28 Oct 2019.

11. Lent H, Wygodzinsky P. Revision of the Triatominae (Hemiptera, Reduviidae), and their significance as vectors of Chagas' disease. Bull Am Museum Nat Hist. 1979;163:1-520.

12. Dujardin J-P, Kaba D, Henry AB. The exchangeability of shape. BMC Res Notes. 2010;3:266.

13. Souza AC, Catalá S, Carbajal-de-la Fuente AL, Junqueira A. Phenotypic variability of the Amazonian species Rhodnius brethesi (Hemiptera: Reduviidae). J Med Entomol. 2017;54:909-16.

14. Catalá SS, Maida DM, Caro-Riaño H, Jaramillo N, Moreno J. Changes associated with laboratory rearing in antennal sensilla patterns of 
Triatoma infestans, Rhodnius prolixus, and Rhodnius pallescens (Hemiptera, Reduviidae, Triatominae). Mem Inst Oswaldo Cruz. 2004;99:25-30.

15. García-Alzate R, Lozano-Arias D, Reyes-Lugo RM, Morocoima A, Herrera L, Mendoza-León A. Triatoma maculata, the vector of Trypanosoma cruzi, in Venezuela. Phenotypic and genotypic variability as potential indicator of vector displacement into the domestic habitat. Front Public Health. 2014;2:170.

16. Luitgards-Moura JF, Vargas AB, Almeida CE, Magno-Esperança G, AgapitoSouza R, Folly-Ramos E, et al. A Triatoma maculata (Hemiptera, Reduviidae, Triatominae) population from Roraima, Amazon Region, Brazil, has some bionomic characteristics of a potential Chagas disease vector. Rev Inst Med Trop Sao Paulo. 2005:47:131-7.
17. Gómez-Melendro EN, Hernández C, González-Uribe C, Brochero H. First record of Triatoma maculata (Erichson, 1848) (Hemiptera: Reduviidae: Triatomini) in the municipality of Riohacha, La Guajira, Colombia. Front Public Health. 2014;2:219.

18. Noireau F, Carbajal-de-la-Fuente AL, Lopes CM, Diotaiuti L. Some considerations about the ecology of Triatominae. An Acad Bras Cienc. 2005;77:431-6.

\section{Publisher's Note}

Springer Nature remains neutral with regard to jurisdictional claims in published maps and institutional affiliations.
Ready to submit your research? Choose BMC and benefit from:

- fast, convenient online submission

- thorough peer review by experienced researchers in your field

- rapid publication on acceptance

- support for research data, including large and complex data types

- gold Open Access which fosters wider collaboration and increased citations

- maximum visibility for your research: over 100M website views per year

At BMC, research is always in progress.

Learn more biomedcentral.com/submissions 